\title{
The motivation of fixed orthodontic appliance patients with two-years of usage time
}

\author{
Paramita Widyandari*, Isnaniah Malik*, Iwa Rahmat Sunaryo* \\ *Department of Orthodontics Faculty of Dentistry Universitas Padjadjaran
}

\section{ABSTRACT}

Introduction: Motivation is the power that moves a person to behave, think, and feel like they do. The patient's motivation when doing orthodontic treatment is essential to determine the success of the treatment. This study aimed to determine the description of the motivation of patients who have been using fixed orthodontic devices for two years at Dental Hospital Universitas Padjadjaran (RSGM Unpad). Methods: This type of research is done by using descriptive methods. The sampling technique is total sampling with the number of research samples obtained was 34 people. This research was conducted during October 2011. The type of patient motivation was determined by using a quartile in scoring the results of the questionnaire answers given to respondents, namely patients who came to the RSGM specialist integrated care facility. Patients' motivation is categorized as very high, high, low, and very low. Results: The results showed that the majority of respondents were women, teenagers and young adults, with high school education and university students. Patient motivation levels obtained from data analysis were only very high and high categories in orthodontic treatment. Conclusion: All the respondents have a relatively high motivation for undergoing orthodontic treatment at the RSGM Unpad and no respondents who have low motivation.

Keywords: Motivation, fixed orthodontic treatment.

\section{INTRODUCTION}

Orthodontics, as Salzmann (1943) defines, is a branch of science and art in dentistry that deals with the development and abnormalities of the position of the teeth and jaws, and affects a person's oral, physical, aesthetic, and mental health. ${ }^{1}$ Orthodontics deals with facial, occlusal developments, as well as matters concerning supervision, control, and also improvements in coping with occlusal problems and dentofacial abnormalities. ${ }^{2}$ The main objective of orthodontic treatment is not only prioritized aesthetic needs but moreover fulfils the functional and physiological interests of the patient.

It has been clear that the primary goal of orthodontic treatment in most patients is to correct dental and facial aesthetic problems. This goal is not only for the sake of cosmetics but also is a reflection of the desire of patients to increase their acceptance in society and to eliminate any discrimination that they may have experienced in the community. ${ }^{3}$ This further confirms that malocclusion provides satisfaction in the patient if the final result obtained must sacrifice the proportion of the face. ${ }^{4}$ According to Nanda (2005), 
a person's facial appearance and attractiveness can significantly influence various aspects of personal, social, and professional life. ${ }^{5}$

Many researchers have found that certain variables have high influence such as age, gender, or social status of patients in deciding to start the treatment. ${ }^{6}$ In general terms, the demand for orthodontic treatment increases in adulthood, usually higher among women, in people with better socioeconomic backgrounds, and when the ratio of orthodontist ratios in a population is small, so orthodontic treatment is of nature became more frequent and the level of acceptance in the community increased. ${ }^{7}$ Aesthetic appearance is one of the biggest reasons for patients to seek orthodontic treatment or orthognathic surgery. ${ }^{8}$ The above shows that patient motivation and satisfaction varies from individual to individual. The patient's motivation in orthodontic treatment is essential when a dentist tries to estimate how much the patient will cooperate during treatment. Previous studies suggest that a lack of motivation in adults has a significant relationship with stopping or obstructing orthodontic treatment. ${ }^{9}$ The purpose of this study was to obtain data on the motivation of patients using fixed orthodontic devices for two years in Integrated Services Installation Specialist Treatment Room of the RSGM Unpad.

\section{METHODS}

This type of research is descriptive research. The study population was patients from the orthodontic department who used fixed appliances and underwent treatment at the Integrated Services Installation Specialist Treatment Room of the Faculty of Dentistry, Padjadjaran University, Bandung since 2009. The sampling technique used in this study was technique total sampling or commonly referred to as the saturation sampling.

The sample taken is part of the population that fits the following criteria: patients treated at the Integrated Services Installation Specialist Treatment Room of RSGM Padjadjaran University Bandung; just started treatment in 2009; not illiterate; understand Indonesian; ready to be as a respondent. Patient motivation is a state of motivation that is felt by the patient in doing orthodontic treatment with fixed devices for two years. In this study, the level of patient motivation was separated according to the amount of the score obtained on each questionnaire that the patient answered into the quartile system: Number of scores in the range of $16-32$ classified in the shallow motivation category; Questionnaire score between 33-48 is included in the low motivation category; Questionnaire score values between 49 64 belong to the high motivation category; and scores between 65-80 in the very high motivation category. Fixed orthodontic treatment is a treatment performed by patients in dealing with occlusal or facial problems they experience.

The tools and materials used during this research were: Stationery; the research instrument in the form of a questionnaire; computer. The research questionnaire was composed of 16 statements. The statements contained in the questionnaire consist of 12 positive statements, namely from numbers 1 to 12 and 4 negative statements at numbers 13 to 16 . In each statement, there are five answer choices, consisting of strongly agree (SS), agree (S), hesitant (RR), disagree (TS), and strongly disagree (STS). The score for each positive statement for the answer $S S=5, S=4$, RR $=3, \mathrm{TS}=2, \mathrm{STS}=1$, while for negative statements given the value of $S S=1, S=2, R R=3, T S=4$, STS $=5$.

The research data was collected and then processed by finding the overall quartile of respondents' scores. Quartile system is obtained by dividing four between the maximum and minimum scores on the questionnaire answered by respondents. The results obtained will be presented in tables and diagrams.

\section{RESULTS}

The study was conducted on 34 general patients who came to the Integrated Services Installation Specialist Treatment Room of the Faculty of Dentistry, Padjadjaran University in the orthodontics section during October 2011. The study was conducted by collecting data from questionnaires given to respondents. Respondent characteristics that will be explained below include gender, age, occupation, and patient education. The following is a description of the characteristics of 34 fixed orthodontic patients 
who have undergone treatment for two years in the Integrated Services Installation Specialist Treatment Room of the Faculty of Dentistry, Padjadjaran University, Bandung. Comparison of the number of male and female respondents will be presented in the diagram as follows.

In the chart above, it can be seen that the majority of respondents who have used fixed orthodontic devices for two years in the Integrated Services Installation of the Dental Care and Mouth Hospital Specialist Hospital of Padjadjaran University are female, as many as 26 people, or $76.5 \%$ of the total 34 respondents the research sample.

Furthermore, in terms of the age of the respondents, the data obtained showed that the majority of respondents were aged 20-25 years, namely as many as 17 people or as much as $50 \%$ of the total 34 respondents who had used fixed orthodontic appliances for two years in the Integrated Services Installation Special Care Room Dental and Mouth Hospital of FKG Padjadjaran University Bandung-followed by respondents who were less than 20 years old, as many as 13

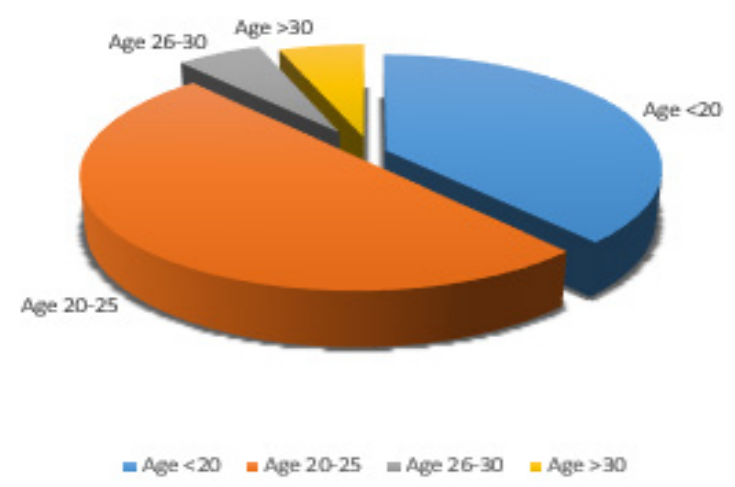

Figure 1. Graph of distribution of respondents by sex

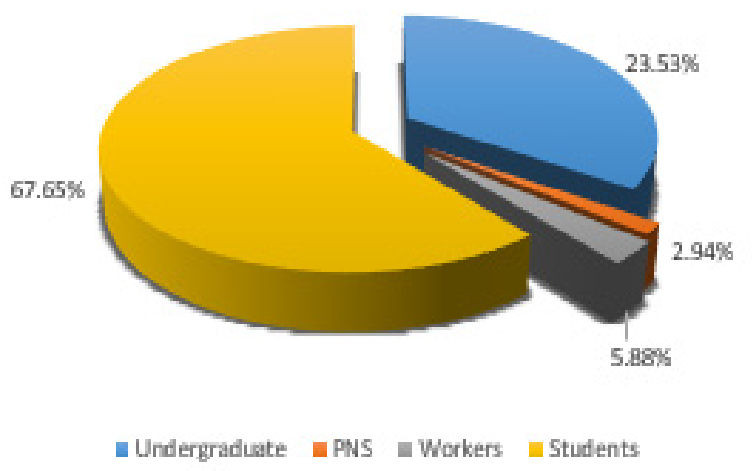

Figure 2. Graph of distribution of respondents by age people or $38.2 \%$ of the total respondents. While respondents who are more than 30 years old are as many as two people or $5.9 \%$ of the total number of respondents, an illustration of the number of respondents by age can be seen in Figure 2 .

If seen from the type of respondent's work, as shown in Figure 4.3, it appears that the majority of respondents are students (S1 \& S2), which is 23 people or $67.65 \%$ of the total 34 respondents. Followed by respondents who are still students, as many as eight people or $23.53 \%$ of the total respondents. Meanwhile, there were only three self-employed respondents and civil servants or $8.82 \%$ of the total number of respondent

Based on respondents' knowledge, as shown in Figure 4.4, the majority of respondents have an education past high school, as many as 20 people or $58.8 \%$ of the total of 34 respondents. Next are respondents who have a junior high school education, as many as eight people or $23.5 \%$ of the total respondents. While respondents with an undergraduate education ( $\mathrm{S} 1$ and $\mathrm{S} 2$ ), there were

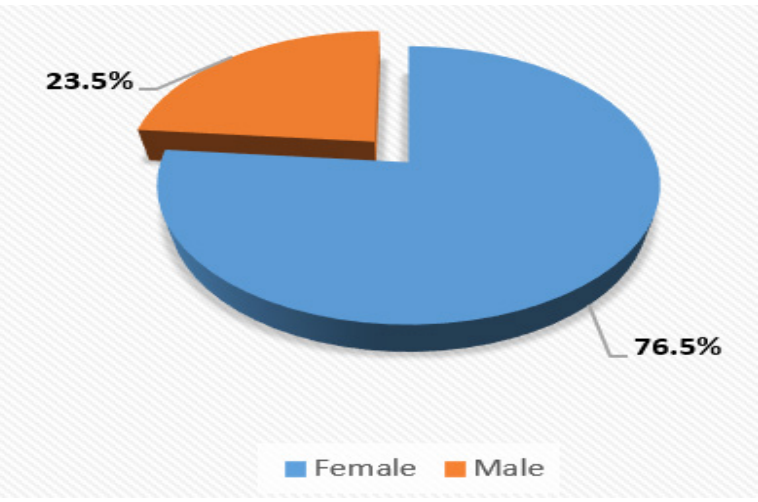

Figure 3. Graph of distribution of respondents based on work

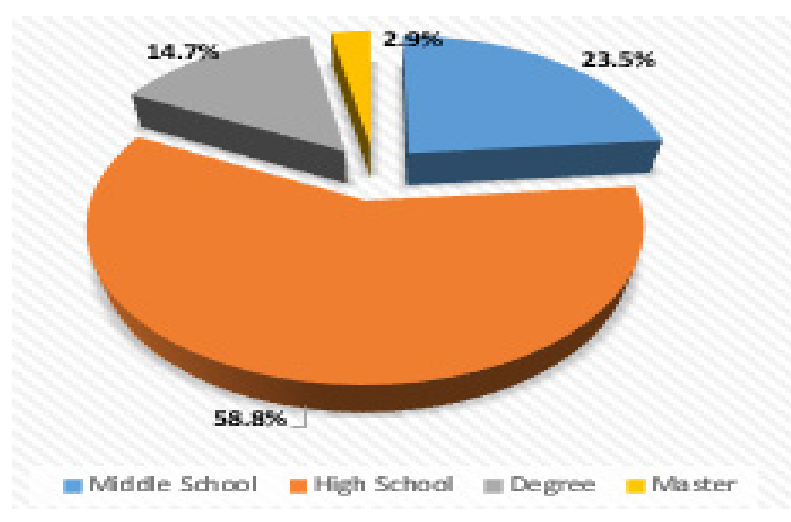

Figure 4. The figure of respondents distribution based on education 


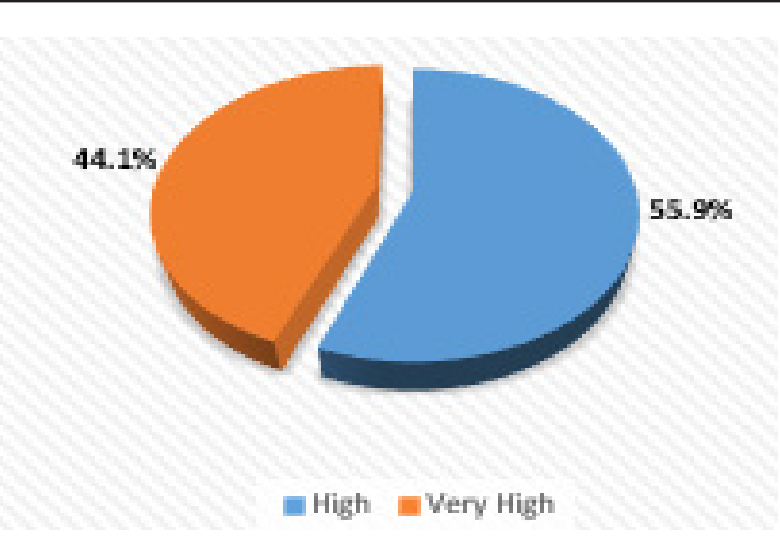

Figure 5. Graph of the distribution of respondents based on motivation

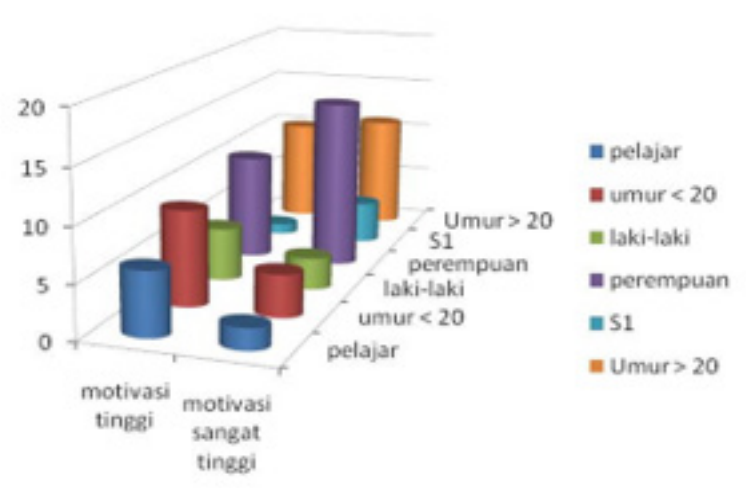

Figure 6. Graph of the distribution of respondents by type of motivation

Table 1. Patient motivation categories for each item statement

\begin{tabular}{|c|c|c|}
\hline Statement & $\Sigma$ Scores & Category \\
\hline Feel my teeth are crammed / not neat / not neat & 138 & Very high \\
\hline Undergo this treatment of your own will & 151 & Very high \\
\hline Undergo this treatment because you know the benefits & 154 & Very high \\
\hline Feel more confident since doing treatment & 138 & Very high \\
\hline Feel my smile more attractive since doing treatment & 130 & High \\
\hline Willing to feel discomfort during treatment & 135 & High \\
\hline Always exercise control according to the schedule set by the doctor & 136 & High \\
\hline Feeling you need regular control time & 141 & Very high \\
\hline Happy to control & 142 & Very high \\
\hline Prioritize control schedules among other activities & 108 & High \\
\hline Diligent control because they know the next treatment steps & 131 & High \\
\hline Diligent control because you want to recover quickly & 148 & Very high \\
\hline Does not require others to remind time control & 125 & High \\
\hline Not only do the controls if you feel there are complaints on the teeth & 140 & Very high \\
\hline Don't feel bored with the treatment because it takes a long time & 113 & High \\
\hline Not feeling control to the dentist is just a waste of time & 149 & Very high \\
\hline
\end{tabular}

only six people or $17.6 \%$ of the total respondents.

The motivation of patients who had been using fixed orthodontic devices for two years in the Integrated Services Installation of the Special Care Room of the Dental and Oral Hospital of Padjadjaran University in Bandung was measured using 16 statements. An overall picture of patient motivation is grouped into four groups, namely Very Low, Low, High, and Very High. Grouping is done using quartiles, namely by dividing the four ranges maximum score with a minimum score. Following are the results of categorizing patient motivation divided by quartiles.

Based on the results of categorization, it turns out that patient motivation is only divided into two groups, namely high and very high. There were 19 highly motivated patients or $55.9 \%$ of the total of 34 respondents. Then 15 people had very high motivation or $44.1 \%$ of the total respondents. This can be interpreted that the majority of patients who have been using fixed orthodontic devices for two years in the Integrated Services Installation of the Special Care Room of the Dental and Oral Hospital of Padjadjaran University in Bandung have high motivation in conducting care. The categories of patient motivation measured in this study are in each statement item presented in the following table.

This study divides respondents into four groups, namely very high motivation, high, low, and also very low. However, with the quartile data analysis process that has been carried out, the respondents examined in this study were only divided into two groups, namely those with high 
motivation and also very high. Respondents in the highly motivated group have many characteristics from among students, who are less than 20 years old and have the latest education from junior high to high school. While in groups respondents who have very high motivation, found that the majority of respondents aged more than 20 years and educated the last $\mathrm{S1}$, as can be seen in Figure 6 .

In Table 1 looks category of patient motivation for each item statement also simply divided into two groups, namely the category of high and very high. In the results of the calculation of data analysis, there are seven items included in the high category, namely the patient feels his teeth are not neat, wants to be treated of his desires, know the benefits of treatment, feel more confident since doing treatment, feel the need for regular control feel happy when doing control, want to recover quickly, and not only control when there are complaints on their teeth. Meanwhile, 9 items are included in the very high category; namely, respondents feel their smile is more attractive since doing treatment, willing to feel discomfort during treatment, always control according to schedule, prioritize control schedule, diligently exercise control, do not need anyone else in reminding time control, and do not feel bored in doing maintenance.

\section{DISCUSSION}

In terms of age, respondents are divided into teenagers to young adults. This situation shows that adolescents and young adults who do more orthodontic treatment than parents or children. For teenagers, appearance gets the most attention, especially the face. Changes in appearance can have an influence on how they feel about themselves, both anxiety and selfconfidence. ${ }^{10}$

Often, the primary motivation for children and adolescents undergoing orthodontic treatment is only an attempt by their parents to provide the best for her children. Not a few of these teens do care passively, just as they have to go to school or even the course. Another case for young adults, aged 20-40 years, most people have a goal to improve the quality of life, so one of them, in this case, is to improve the appearance both dental and facial which is expected to overcome social problems that may be experienced. ${ }^{4}$ This is consistent with the results of the research mentioned above.

When viewed in terms of the sex of the respondents separately, which can also be seen in Figure 6, the number of men in the highly motivated group of respondents is higher than in the very high group. Unlike the case with women, more women have very high motivation compared to those who have high motivation. This illustrates that women are more motivated to undergo orthodontic treatment than men. The situation is in line with research conducted by Jones et al. (2004), he states that women pay more attention to appearance problems than men. ${ }^{11}$ Besides, he also believes that more women feel dissatisfied with the state of their body, which, when linked in this study is the condition of their teeth.

The types of work of respondents in this study were mostly students and students. Therefore, it can be seen that many of the respondents here do not have their income, but come from families that are well-off or very well-off. This is the same as revealed by Heasman (2003) that orthodontic treatment is influenced by several factors, one of which is the social class of the patient. ${ }^{2}$

Overall respondents of this study were well educated, as seen from the majority of respondents who were still educated according to their respective ages and also some respondents who had completed their tertiary education such as S1 or S2. Because most of the respondents aged 20-25 years, the highest educated high school occupies the highest position of the number of respondents in this study.

High or low level of someone's education greatly influences their behaviour in doing something, including health behaviour. The higher the level of one's education, the better his awareness about health, and so the better the health care he is undergoing. ${ }^{12}$ Besides, someone who has higher knowledge, will usually be more motivated because he has broader insight than people who have lower knowledge. ${ }^{13}$

After knowing how gender, age, occupation, and education can influence a person's behaviour and motivation, it can be seen that in this study the behavior and motivation for orthodontic treatment are also affected by these things. 
If viewed as a whole, respondents have high motivation and very high is supported by the background of more respondents' women, the age of respondents ranging from adolescents to young adults, and the high social class and education of respondents. This is in accordance with the opinion of Heasman (2003), which states that when viewed in general, the demand for orthodontic treatment increases in adulthood, usually higher among women, in people with better socioeconomic backgrounds, and when compared the orthodontic ratio in a population is small, so orthodontic treatment becomes more prevalent and the level of acceptance in society increases. ${ }^{2}$

From table 1 can be seen that the statement that best demonstrates a very high motivation is number 3 , in which patients this treatment because it knows very well benefit from her treatment, which means the same as the purpose of the implementation of the treatment. This is consistent with what was stated by Gustisyah (2009), that motivation consists of 3 elements, namely encouragement, needs, and goals. ${ }^{13} \mathrm{King}$ (2010), also states that needs are something that underlies our drive. ${ }^{14}$ In connection with this research, because someone already knows the objectives to be achieved, then there can be an encouragement and the need for orthodontic care he does to achieve these goals. Motivated behaviour can be formulated as a behaviour that is motivated by the existence of needs and directed towards the achievement of objectives so that needs are met, and wants are satisfied. ${ }^{15}$

Boredom or boredom experienced by someone can affect someone in doing something, and in the end, it will affect his motivation too. ${ }^{13}$ In this study, data analysis shows statement number 15, which is the boredom that is felt by patients during treatment, has quite a large amount. However, the total score is the least, so it is still classified as high motivation.

What patients expect from the success of the treatment is closely related to the type of motivation and must be carefully known among adults, especially those who have major complaints about cosmetic problems. ${ }^{4}$ From the results of studies that show high motivation of patients who have been undergoing fixed orthodontic treatment for two years, we can get a pretty high chance of successful treatment. Besides, high patient motivation can also lead to a good level of cooperation during treatment, according to the statement of Daniels, et al ., (2009), namely the patient's motivation in orthodontic treatment is essential when a dentist tries to estimate how big a patient is it will be cooperative during treatment.

\section{CONCLUSION}

All respondents had relatively high motivation during orthodontic treatment at RSGM, and none of the respondents had low motivation.

\section{REFERENCES}

1. Singh, G. Textbook of Orthodontics. 2nd ed . New Delhi: Jaypee Brothers Medical Publishers. 2007. 3-4 pp.

2. Heasman, P. Master of Dentistry vol.2. Toronto: Churchill Livingstone. 2003. 227 pp.

3. Graber, TM, Robert LV, and Katherine WLV Orthodontics: Current Principles Techniques . Missouri: Elsevier. 2005. 3 pp.

4. Proffit, WR, Henry WF JR., David MS Contemporary Orthodontics. 4th ed . Missouri: Elsevier. 2007. 3, 5, 235, 410 pp.

5. Nanda, R. Biomechanics and Esthetic Strategies in Clinical Orthodontics. Missouri: Elsevier. 2005. $94 \mathrm{pp}$.

6. Watted, N .; Emil W .; Josip SB A Therapeutic Concepts For The Combined Orthodontic Surgical Correction Of Angle Class II Deformities With Short-Face Syndrome: Surgical Lengthening of The Lower Face. Clin Orthod. Res. 3, 2000; 78-93.

7. Heasman, P. Master of Dentistry vol.2. Toronto: Churchill Livingstone. 2003. 227 pp.

8. Vargo, JK et al. Association between ratings of facial attractiveness and patients' motivation for orthognathic surgery . Orthod Craniofacial Res 6, 2003; 63-71.

9. Daniels, A. S, et al. Orthodontic treatment of motivation and cooperation: A cross-sectional analysis of adolescent patients 'and parents' responses. Am J Orthod Dentofacial Orthop 2009; 136: 780-7.

10. Bishara, SE Textbook of Orthodontics. Pennsylvania: WB Saunders Company. 2001. 98, 104, 106-108, 232 pp

11. Jones, DC; Thorbjorg HV; and Yoonsun 
L. Body Image and Apperance Culture Among Adolescent Girls and Boys: An Examination of Friend Conversation, Peer Criticism, Appearance Magazines, and The Internalization of Appearance Ideals. Journal of Adolescent Research 2004 19: 323.

12. Notoatmodjo, S. Public Health Sciences . Jakarta: PT. Rineka Cipta. 2003. 46.

13. Gustisyah, R. Analysis of Factors Affecting the Work Motivation of Industrial
Extension Workers at Medan City Industry and Trade Office . Medan: Thesis of the University of North Sumatra . 2009

14. King, LA General Psychology An Appreciative View . Jakarta: Salemba Humanika. 2010. h. 64-65, 90.

15. Himawati, A. Comparison of Intrinsic and Extrinsic Motivation in Removable Orthodontic Patients in FKG UNPAD Student Work Clinic . Bandung: Thesis UNPAD. 1999 